\title{
Step change improvements in high-temperature thermocouple thermometry
}

\author{
Professor Graham Machin \\ Head, Temperature Standards \\ Engineering Measurement Division \\ National Physical Laboratory \\ Hampton Road, Teddington, Middlesex, TW11 0LW, UK \\ graham.machin@npl.co.uk
}

\author{
Dr Jonathan Pearce \\ Engineering Measurement Division \\ National Physical Laboratory \\ Hampton Road, Teddington, Middlesex, TW11 0LW, UK \\ jonathan.pearce@npl.co.uk
}

\begin{abstract}
Thermocouples are the most widely used and most widely misunderstood temperature sensor in industry. This paper will begin with an introduction to thermocouples, how they work and the different types of thermocouple. The commonest and most misunderstood source of uncertainty, thermoelectric homogeneity, will be described. The paper will then discuss the concept of measurement traceability and new calibration methods that can give $<1{ }^{\circ} \mathrm{C}$ uncertainty up to $1500{ }^{\circ} \mathrm{C}$. The paper will conclude by describing some thermocouple innovations; a) industrial versions of pure thermoelement types (Pt/Pd) and b) self-validating "smart-sensors" which enable thermocouples to remain in calibration even when operating at extreme temperatures e.g. tungsten rhenium (W-Re) refractory metal types (e.g. type $\mathrm{C}$ ) above $2200{ }^{\circ} \mathrm{C}$.
\end{abstract}

Keywords- energy efficiency, industrial process, process control, smart sensors, high temperatures, thermocouples, calibration, traceability, uncertainty

\section{INTRODUCTION}

Thermocouples are used extensively in industry for process control. The reliable manufacture of, for example, iron and steel, glass, semiconductors, carbon and carbon composites, ceramics, refractory metals and nuclear fuel is dependent upon thermocouples. However thermocouples drift and degrade with use. If this drift can be ameliorated or reduced then the processes would run more optimally, so reducing energy consumption and improving product quality. New developments in thermocouples in particular, improved calibration, a new thermocouple type and approaches to selfvalidation at very high temperatures will lead to improved thermometry for more effective industrial production.

Most thermocouples in common use are identified by a letter designation. Thermocouples for industrial process control at high temperatures fall broadly into three categories, dependent upon the wires used for the thermoelements. Below $1300{ }^{\circ} \mathrm{C}$ base metal (nickel alloy) type $\mathrm{K}$ and increasingly, due to better stability, type $\mathrm{N}$ are used. Above those temperatures and up to about $1700{ }^{\circ} \mathrm{C}$ noble metal thermocouples (based on $\mathrm{Pt}$ and/or Pt/Rh alloys) are used; these are designated type $\mathrm{S}, \mathrm{R}$ and B. Then finally, at still higher temperatures refractory metal thermocouples (based on alloys of tungsten (W) and Rhenium (Re)) are used up to approximately $2300{ }^{\circ} \mathrm{C}$.

The foundation of reliable temperature measurement is traceability to an internationally recognized temperature scale. This is currently the International Temperature Scale of 1990 (ITS-90) [1]. All temperature measurement should be traceable to ITS-90 to ensure equivalence. This means that sensors should be calibrated to this temperature scale. In practice (and in particular) base metal thermocouples are manufactured to a specified tolerance and should, at least when new, give reliable temperature measurement. The wires or cables are batch tested before thermocouples are manufactured to ensure that they meet the required specification. Calibration is generally performed against reference thermometers in an isothermal calibration environment. The noble metal thermocouples, which are often the reference sensors, are calibrated against fixed points of known temperature. Recent innovations in the approach to thermocouple calibration, and in particular the advent of completely new fixed points, have meant that lower uncertainty and more reliable calibrations can be performed at least to $1500{ }^{\circ} \mathrm{C}$ - for noble metal thermocouples.

In addition, it is known that type $\mathrm{S}, \mathrm{R}$ and $\mathrm{B}$ thermocouples drift due to the alloy nature of one or both of the thermoelements. The recently developed pure thermoelement robust thermocouple based on platinum and palladium wires (the $\mathrm{Pt} / \mathrm{Pd}$ thermocouple) is not subject to this source of drift and can give considerably more reliable results than the traditional noble metal thermocouples to $1500{ }^{\circ} \mathrm{C}$.

At higher temperatures, and in particular above $1700{ }^{\circ} \mathrm{C}$, refractory metal thermocouples (based on alloys of $\mathrm{W}$ and $\mathrm{Re}$ ) are used for process control. However this type of thermocouple can experience significant drift in use leading to non-optimal control. Very recent work, particularly at NPL, has led to the development of self-validation where thermocouples such as these can be continually calibrated in process leading to a factor 10 or more improvement in their inuse performance.

Beginning with a short introduction to the temperature scale and the calibration of thermocouples this paper will describe how new high temperature fixed points (HTFPs) have improved thermocouple calibration to $1500{ }^{\circ} \mathrm{C}$, how the 
innovation of robust $\mathrm{Pt} / \mathrm{Pd}$ thermocouples opens up the possibility of better temperature sensing and control to that temperature and how the implementation of self-validation at very high temperatures will make a step change improvement in the practice of high temperature contact thermometry.

\section{THE INTERNATIONAL TEMPERATURE SCALE OF 1990 (ITS-90) AND CALIBRATION}

\section{A. The ITS-90}

The ITS-90 is the current temperature scale in use throughout the world, and all reliable temperature measurement is established through traceability to it. The ITS-90 ranges from $0.65 \mathrm{~K}$ above absolute zero, or $-272.50{ }^{\circ} \mathrm{C}$, to the highest temperatures $\left(>3000{ }^{\circ} \mathrm{C}\right)$ for practical thermometry. The purpose of the ITS-90 is to define procedures by which certain specified practical thermometers can be calibrated in such a way that the values of temperature obtained from them are precise and reproducible, while at the same time approximating the corresponding thermodynamic (ideal) values as closely as possible. The "specified practical thermometers" are platinum resistance thermometers (PRT) from about $13.8 \mathrm{~K}\left(-259.4{ }^{\circ} \mathrm{C}\right)$ to the freezing point of pure silver $\left(961.78^{\circ} \mathrm{C}\right)$ and radiation thermometers at higher temperatures. These thermometers are calibrated against a series of fixed points which are generally either triple points (e.g. argon, mercury, water), freezing points (e.g. silver, zinc, tin, indium) and in one case (gallium) a melting point. These have defined temperatures, formally with zero uncertainties. Below the silver point a calibration essentially determines the resistance ratio of the PRT at a specified set of fixed points relative to the water triple point. At and above the silver point the ITS-90 is established by noncontact thermometry using Planck's law in ratio form. A blackbody of either $\mathrm{Ag}$, $\mathrm{Au}$ or $\mathrm{Cu}$ is used to provide the foundation for the ITS-90 in that range. The interested reader should consult references $[1,2]$ for further information about the ITS-90.

\section{B. The calibration of thermocouples}

Calibration as applied to temperature measurement can be defined as 'the set of operations which establish, under specified conditions, the relationship between values indicated by a thermometer and the corresponding known values of temperature' adapted from [3].

There are two principal types of calibration: comparison calibration, and fixed-point calibration. In a comparison calibration, the environment may be a variable-temperature bath or furnace which can be controlled at the desired uniform temperature. The thermometers to be calibrated are inserted into the environment along with standard thermometers which are calibrated in terms of the ITS-90, and measurements are made in an appropriate sequence. In this way the readings of the thermometers under calibration are related to the temperature as determined by the standards.
Fixed-point calibrations are generally more precise and demanding than comparison calibrations. Typically the fixedpoint temperature is given by the freezing points (except gallium where the melting point is used) of pure materials, whose temperatures are defined in the ITS-90 (see Section II.A above). Generally the metallic fixed-points are in a state of nearequilibrium between the liquid and solid phases of a pure substance at a pressure of one standard atmosphere. The only exception to this is the mercury fixed-point where the triple point is realised. The freezing point technique requires heating the cell to about 5 to $10{ }^{\circ} \mathrm{C}$ above the melting temperature, insertion of a monitoring thermometer which indicates when the metal ingot is completely melted. The ingot is then slowly cooled while continuously logging the output of the monitoring thermometer. After an initial supercool the temperature rises to the freezing-point. The calibration measurements are made in the ensuing flat portion, or plateau, of the freezing curve, so giving the calibration of the thermometer at the freezing point. Typical fixed point materials used in the calibration of thermocouples are zinc $\left(419.527^{\circ} \mathrm{C}\right)$, aluminium $\left(660.323^{\circ} \mathrm{C}\right)$, silver $\left(961.78{ }^{\circ} \mathrm{C}\right)$ and copper $\left(1084.62^{\circ} \mathrm{C}\right)$.

A discussion of what thermocouples are and how they work is deferred until Section IV.

\section{HIGH TEMPERATURE FIXED POINTS, HTFPS}

For the purpose of clarity HTFPs are those that operate above the freezing point of $\mathrm{Cu}\left(1084.62{ }^{\circ} \mathrm{C}\right)$ and are based on various types of binary alloys of metal (or metal-carbide) and carbon [4, and references therein]. These are new fixed points, under development in the last 10 years, and as such they have not yet had formal temperatures assigned to them. Table 1 lists the reported fixed-points to date, with their nominal transition temperatures.

The performance of HTFPs has been well characterised, particularly the repeatability and the reproducibility of their realised temperatures. A typical melt and freeze curve for a $\mathrm{HTFP}(\mathrm{Co}-\mathrm{C})$ is given in Fig. 1.

Repeatability is a measure of how repeatable the temperature of an individual HTFP is when realized in quasiidentical conditions. That is, if a HTFP was melted in a furnace, then immediately frozen and melted again in the same furnace, repeatability is a measure of the agreement between the two melt temperatures. It is clear that individual HTFPs are highly repeatable, of the order of $0.02{ }^{\circ} \mathrm{C}$ even at the highest temperatures [4].

Reproducibility is a more exacting criterion than repeatability. It is a measure of the agreement in the melting temperature of two samples of HTFP material, especially if manufactured by two different suppliers. Good reproducibility is attainable when impurities in the metal of the ingot are carefully controlled. For example it has been shown that for $\mathrm{Co}-\mathrm{C}, \mathrm{Pt}-\mathrm{C}$ and $\mathrm{Re}-\mathrm{C}$ reproducibility of better than $0.1^{\circ} \mathrm{C}$ can easily be achieved [5]. 
TABLE 1: METAL-CARBON, METAL-CARBIDE-CARBON AND METAL-CARBIDE-CARBON PERITECTICS WITH NOMINAL TEMPERATURES [6]

\begin{tabular}{|c|c|c|}
\hline Eutectic & $\begin{array}{l}\text { Approximate } \\
\text { temperature / K }\end{array}$ & $\begin{array}{l}\text { Approximate } \\
\text { temperature/ }{ }^{\circ} \mathrm{C}\end{array}$ \\
\hline \multicolumn{3}{|c|}{ Metal-carbon } \\
\hline $\mathrm{Fe}-\mathrm{C}$ & 1426 & 1153 \\
\hline $\mathrm{Co}-\mathrm{C}$ & 1597 & 1324 \\
\hline $\mathrm{Ni}-\mathrm{C}$ & 1602 & 1329 \\
\hline $\mathrm{Pd}-\mathrm{C}$ & 1765 & 1492 \\
\hline $\mathrm{Rh}-\mathrm{C}$ & 1930 & 1657 \\
\hline $\mathrm{Pt}-\mathrm{C}$ & 2011 & 1738 \\
\hline $\mathrm{Ru}-\mathrm{C}$ & 2227 & 1954 \\
\hline Ir-C & 2565 & 2292 \\
\hline $\mathrm{Re}-\mathrm{C}$ & 2747 & 2474 \\
\hline \multicolumn{3}{|c|}{ Metal-carbide-carbon } \\
\hline $\mathrm{B}_{4} \mathrm{C}-\mathrm{C}$ & 2659 & 2386 \\
\hline$\delta(\mathrm{MoC})-\mathrm{C}$ & 2856 & 2583 \\
\hline TiC-C & 3032 & 2759 \\
\hline $\mathrm{ZrC}-\mathrm{C}$ & 3155 & 2882 \\
\hline HfC-C & 3458 & 3185 \\
\hline \multicolumn{3}{|c|}{ Metal-carbide-carbon peritectic } \\
\hline $\mathrm{Mn}_{7} \mathrm{C}_{3}-\mathrm{C}$ & 1604 & 1331 \\
\hline $\mathrm{Cr}_{3} \mathrm{C}_{2}-\mathrm{C}$ & 2099 & 1826 \\
\hline WC-C & 3022 & 2749 \\
\hline
\end{tabular}

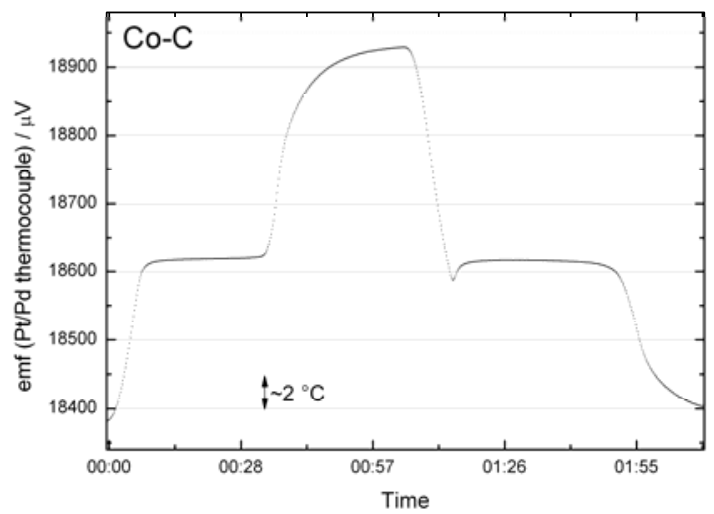

Figure 1: Melting and freezing curve of an NPL Co-C point as measured by a $\mathrm{Pt} / \mathrm{Pd}$ thermocouple. The $\mathrm{x}$-axis is time in hours:minutes..
The main use of HTFPs to date has been comparing high temperature scales for radiation thermometry [e.g. 5] and the calibration of thermocouples to $1500{ }^{\circ} \mathrm{C}$. NPL now has fully implemented ISO 17025 calibration of noble metal thermocouples using HTFP ingots of $\mathrm{Co}-\mathrm{C}$ and $\mathrm{Pd}-\mathrm{C}$. The accredited uncertainty of noble metal thermocouple calibrations is $0.5{ }^{\circ} \mathrm{C}(k=2)$ at $1324{ }^{\circ} \mathrm{C}$ (the Co-C point) and $0.7{ }^{\circ} \mathrm{C}(k=2)$ at $1492{ }^{\circ} \mathrm{C}$ (the Pd-C point). To obtain the lowest uncertainty calibration for industrial customers accredited laboratories are beginning to implement HTFPs within their calibration process as well [7].

\section{THERMOCOUPLES}

In this section we describe briefly what thermocouples are, how they work and the various types. The common and often largest source of uncertainty, that due to inhomogeneity is discussed. Then the pure thermoelement thermocouple based on Pt and Pd will be introduced and its superior performance described.

\section{A. Thermocouples what they are and how they work}

Thermocouples are made of two dissimilar wires joined together at the measurement junction. As the wires pass through a region where the temperature changes (i.e. where there is a temperature gradient) they generate an emf, or thermovoltage. This is the Seebeck effect, named after its discoverer, and its magnitude, typically about $10-40 \mu \mathrm{V} /{ }^{\circ} \mathrm{C}$, depends on the Seebeck coefficients of the thermocouple wires and the temperature difference along the total length. The emf can be measured by connecting the wires to a voltmeter. However, it depends on the temperature at the cold end, so for the most accurate measurements the wires are connected to copper leads and placed in melting ice to form the 'reference junction', and the copper wires are then connected to the voltmeter. Fig. 2 is a schematic circuit diagram of a thermocouple of wires $a$ and $b$ measuring temperature $t_{1}$, with reference junctions connected to copper wires at temperature $t_{\text {ref }}$, generating an emf, $E$.

It is important to remember that the emf is not generated at the measurement junction but in the region where the thermocouple experiences a temperature gradient. So for example when a thermocouple is being calibrated in a furnace most of the emf is generated in the region where the thermocouple emerges from the furnace, not in the isothermal part where the measuring junction is [8].

This is such an important point it is worth discussing in detail. The emf generated at any point along the wire can be written as the product of the Seebeck coefficient, $S(t)$ and the temperature gradient at that point $d t$. The total emf is found by adding the emfs $S(t) d t$ generated at all points along the length, starting from the reference junction and continuing to the measuring junction. Mathematically this is expressed as integrating $S(t) d t$ from $t_{r e f}$ to $t_{1}$. As what is measured is the difference between the emfs generated in the two wires of the thermocouple, with different Seebeck coefficients $S_{a}$ and $S_{b}$, the total emf, $E$, is the difference between two integrals (1): 


$$
E=\int_{t_{\text {ref }}}^{t_{1}} S_{a} d t-\int_{t_{\text {ref }}}^{t_{1}} S_{b} d t=\int_{t_{\text {ref }}}^{t_{1}}\left(S_{a}-S_{b}\right) d t
$$

In the simple case where the two Seebeck coefficients are independent of temperature, the equation reduces to (2)

$$
E=\left(S_{a}-S_{b}\right)\left(t_{1}-t_{r e f}\right)
$$

so the emf is just the product of the difference in the two Seebeck coefficients and the temperature difference between the ends of the wires. This does not mean that the emfs are generated at the junctions but, as we have emphasized, the two junction temperatures are just the start and finish of the integration, or summation of emfs in the circuit.

Note that in the circuit of Fig. 2, the two copper wires, c, ideally produce equal and opposite emfs, so they do not contribute to the total result. Note also that, rather than use ice, these days an automatic electronic ice-point is often used. More commonly, however, the thermocouple wires are directly connected to instrumentation that has automatic 'cold-junction compensation'.

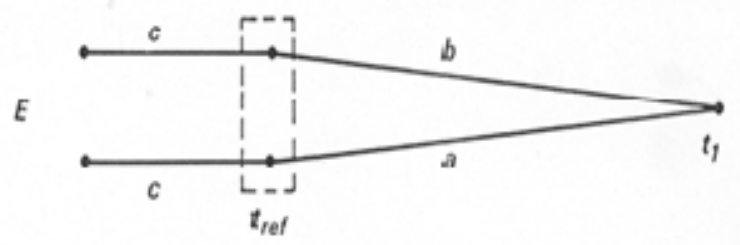

Figure 2: Schematic circuit diagram of a thermocouple being used to measure $t_{1}$, from [9]. The letters $a$ and $b$ represent two different types of thermoelement, letter $c$ represents the copper wires and $t_{\text {ref }}$ the reference temperature - usually the ice point.

Provided that the junctions are isothermal, i.e. that there are no temperature gradients near them, the way in which they are made is not important; they can be twisted, clamped, soldered or welded together. The important point is that they must be isothermal and sufficiently robust to keep the wires connected together thus completing the circuit.

\section{B. Types of thermocouples}

There are many types of thermocouple, and several are standardized and recognized by a letter designation. They also fall into three broad categories depending upon the metal the thermoelements are made from; these are base metal, noble (or precious) metal and refractory metal.

In base metal types for relatively low temperature applications, designated type $\mathrm{T}, \mathrm{J}$ and $\mathrm{E}$, the thermoelements are made of copper or copper-nickel alloys. For example the type $\mathrm{T}$ has a positive thermoelement of pure $\mathrm{Cu}$ and a negative thermoelement made of copper alloyed with about $45 \%$ nickel. This thermocouple is known as the copper-constantan thermocouple. Base metal types for higher temperature applications, up to $1300{ }^{\circ} \mathrm{C}$, are designated types $\mathrm{K}$ and $\mathrm{N}$. Here the thermoelements are based on nickel alloys. The type
$\mathrm{N}$ positive thermoelement is Nicrosil from an alloy of $\mathrm{Ni}, \mathrm{Cr}$ and $\mathrm{Si}$, the negative thermoelement is Nisil, made from an alloy of $\mathrm{Ni}$, Si and $\mathrm{Mg}$.

Noble metal thermocouples (generally for high temperature applications) can be used continuously in oxidizing atmospheres up to about $1600^{\circ} \mathrm{C}$. They are designated types $\mathrm{S}$, $\mathrm{R}$ and $\mathrm{B}$ and the thermoelements are based on pure platinum and varying proportions of $\mathrm{Pt}-\mathrm{Rh}$ alloy. For example the type $\mathrm{R}$ thermocouple has a positive thermoelement of Pt alloyed with $13 \% \mathrm{Rh}$ and a negative thermoelement made of pure Pt. There is also the pure thermoelement thermocouple $\mathrm{Pt} / \mathrm{Pd}$ (see Section IV:D below) which has superior performance to other the noble metal alloy types, in particular circumstances, but its top temperature is limited to $1500{ }^{\circ} \mathrm{C}$.

Refractory metal thermocouples are generally used above $1300{ }^{\circ} \mathrm{C}$ where noble metal thermocouples are too expensive for the application, and above $1600{ }^{\circ} \mathrm{C}$ to approximately $2300{ }^{\circ} \mathrm{C}$ where no other thermocouples are available for use. They are designated types $\mathrm{C}, \mathrm{G}$ and $\mathrm{D}$ and the thermoelements are constructed from tungsten and/or various alloys of tungsten and rhenium. The most common refractory metal thermocouple, type $\mathrm{C}$, is made from $\mathrm{W} 5 \% \operatorname{Re}$ (positive thermoelement) and W26\%Re (negative thermoelement).

Thermocouples are manufactured to different tolerance classes depending on how closely they match the specified emf. The best is tolerance class I ranging to tolerance class III for some thermocouples. More details can be found elsewhere [10] but for illustrative purposes a tolerance class $I$ type $R$ thermocouple has a tolerance value of $\pm 1{ }^{\circ} \mathrm{C}$ in the temperature range $0{ }^{\circ} \mathrm{C}$ to $+1100^{\circ} \mathrm{C}$.

The purpose of this section was to give an introduction to the operation of thermocouples and the standard thermocouple types. More information can be found in classic texts such as Kinzie [8] or at $[9,10,11]$. The rest of this section will describe a common source of uncertainty, often the largest, and often not identified, the thermoelectric inhomogeneity and will conclude by describing the construction and performance of the non-letter designated $\mathrm{Pt} / \mathrm{Pd}$ thermocouple.

\section{Uncertainty arising from thermoelectric inhomogeneity}

As discussed in Section IV:A the thermovoltage from a thermocouple is generated where it experiences temperature gradients. In industrial applications this means that the thermovoltage is usually generated when the thermocouple passes through a furnace wall to the outside environment.

The manufacture of thermocouple wires is carefully controlled so that when new the wires are homogenous (uniform) in alloy and (particularly noble metal types) are generally annealed so that strain is removed. However in use several things happen to disturb the freshly constructed state. Examples are; non-uniform contamination of the wires from the external environment, movement of the alloying materials within the wires and crystal growth within the wires. These effects mean that after use the wires are no longer homogeneous in composition, and the effect of this is magnified when used at high temperatures. 
The consequence of the wire being non-uniform in composition or crystal structure (or both) is that the Seebeck coefficient varies with position along the wire. This means that if the affected part of the thermocouple is where the temperature gradient is, the generated thermovoltage will be in error with a consequent error in the measured temperature. This effect can be quite severe, in base and refractory metal thermocouples, $>10^{\circ} \mathrm{C}$ errors are not uncommon.

Finally the problem of inhomogeneity means that it is not appropriate to remove base metal thermocouples for recalibration. Unless the thermocouple experiences the same thermal environment as in use, a recalibration will fail to properly account for inhomogeneities. To effect a proper recalibration the thermocouple should be calibrated in-situ with a freshly calibrated thermocouple brought alongside in the same thermal environment. However it is usually more cost effective to replace the used thermocouple with a new one of the same type and tolerance classification according to a set maintenance schedule.

\section{Pt/Pd thermocouples}

A relative newcomer is a thermocouple based on thermoelements of pure platinum and palladium, the $\mathrm{Pt} / \mathrm{Pd}$ thermocouple [12]. Although this has been around for some time it has not been widely used outside the laboratory environment because the measurement junction has up to now been made using a stress relieving coil of very fine platinum wire (typically $0.1-0.2 \mathrm{~mm}$ diameter) to accommodate the dissimilar thermal expansivities of the thermoelements. If this had not been allowed for, unacceptable strain would have been introduced into the thermocouple leading to a failure of the measurement junction. The introduction of the coil was gave access to the full performance of the thermocouple but its drawback was that it made the thermometer very fragile and unsuited to industrial applications.

Recent innovations in design, without the stress-relieving coil, have been trialed and demonstrate similar performance to the original versions [e.g. 13]. This development opens up very interesting application possibilities for these sensors that were not possible previously. It can be envisaged that in the near term these robust thermocouple versions will act as scale transfer devices from National Measurement Institutes to accredited laboratories - but with lower uncertainties than are possible with current type $\mathrm{S}, \mathrm{R}$ or $\mathrm{B}$ thermocouples. It can also be envisaged that they will be used as the high temperature scale comparison device of choice between NMIs to $1500{ }^{\circ} \mathrm{C}$. In the longer term it is envisaged that use of $\mathrm{Pt} / \mathrm{Pd}$ thermocouples in industry may well become widespread as the lower sensor cost and improved process control overcome industries' inertia to change.

To take full advantage of the performance of this thermocouple a means had to be found to calibrate it at the highest temperature of operation (about $1500{ }^{\circ} \mathrm{C}$ ). Until HTFPs became available this was not possible because there were no fixed points that could be used, but, with the advent of fixed points of $\mathrm{Co}-\mathrm{C} \quad\left(1324^{\circ} \mathrm{C}\right)$ and $\mathrm{Pd}-\mathrm{C} \quad\left(1492^{\circ} \mathrm{C}\right) \quad \mathrm{Pt} / \mathrm{Pd}$ thermocouples can now be calibrated with low uncertainties over their whole operating range, as described in the preceding section, with remarkably low uncertainties.

A study of robust $\mathrm{Pt} / \mathrm{Pd}$ thermocouples in an industrial laboratory environment showed that they exhibited no significant drift, compared to type $\mathrm{R}$ thermocouples, from their as-new calibrated state, even when experiencing over 300 hours of high temperature exposure (to $1300^{\circ} \mathrm{C}$ ) [14].

\section{SELF VALIDATION OF THERMOCOUPLES AT VERY HIGH TEMPERATURES}

It is well known that thermocouples drift significantly at high temperatures. For example Fig. 3 shows the drift of a WRe thermocouple (type $C$ ) when exposed to temperatures near $2000{ }^{\circ} \mathrm{C}$ over a number of hours [15]. There is a dramatic shift of about $90{ }^{\circ} \mathrm{C}$ in the first 5 hours but even after that large shift there is still an erratic output - e.g. the step upwards in output of about $20^{\circ} \mathrm{C}$ at about 30 hours.

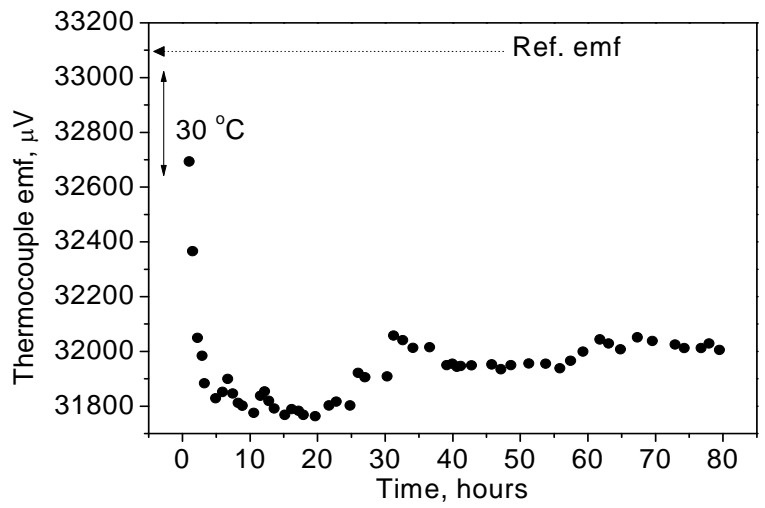

Figure 3. The emf of a new type $\mathrm{C}$ thermocouple as a function of time at temperature $>1950{ }^{\circ} \mathrm{C}$. An emf shift is about $90{ }^{\circ} \mathrm{C}$ after about only $5 \mathrm{~h}$ is clearly observable.

This large and often undetected drift can be very detrimental to the control of an industrial process, particularly in terms of energy efficiency and product quality. The selfvalidation of temperature sensors has been implemented at lower temperatures for a number of years [16], but this was not really possible at higher temperatures until the advent of HTFPs. Here we introduce the principles of self-validation and then how this is implemented in practice with W-Re thermocouples.

\section{A. The principle of self-validation}

Refractory metal thermocouples are the only practical contact temperature sensor above $1700{ }^{\circ} \mathrm{C}$. However there are several problems with their implementation that currently limits their attainable uncertainty. When new the standard tolerance of such thermocouples is $1 \%$, that is $20^{\circ} \mathrm{C}$ at $2000{ }^{\circ} \mathrm{C}$ [17]. Removal for recalibration is not possible for two reasons. Firstly on use the thermoelements become very brittle: if the sensor was then removed it would almost certainly break. Secondly when used the W-Re thermocouple experiences strong inhomogeneity growth rendering, as described above, any calibration except in-situ calibration of little or no use. 
It is clear that the W-Re thermocouple is beset with major performance limitations. One way to overcome all of these is to implement self-validation. That is to incorporate within the thermocouple a reference of known temperature. Then every time the sensor passes through the melting point of the temperature reference its thermovoltage is calibrated allowing the whole output of the thermocouple to be normalized. In this way the thermocouple performance is optimized even at the very highest temperatures.

\section{B. Application of self-validation to high temperature thermocouples}

Self-validation of high temperature thermocouples requires the application of high temperature stable references. The HTFPs described in earlier sections are ideal for this application. Miniature fixed points of $\mathrm{Co}-\mathrm{C}, \mathrm{Pt}-\mathrm{C}, \mathrm{Ru}-\mathrm{C}$ and Ir$\mathrm{C}$ have been produced; these are shown in Fig. 4.
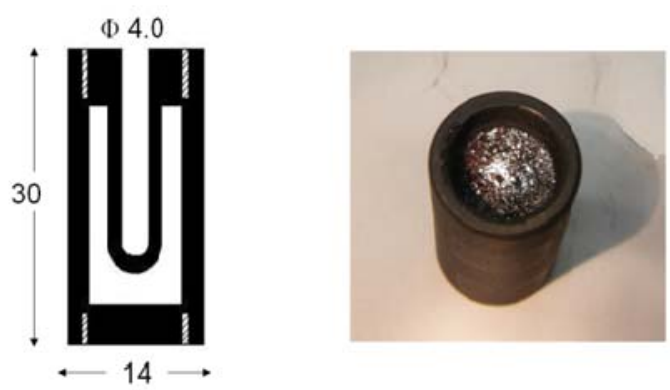

Figure 4: Cross-sectional diagram of a mini HTFP ingot used in selfvalidation studies of W-Re thermocouples [15].

These miniature HTFP ingots are then incorporated with the measurement junction of a metal-sheathed (usually tantalum) W-Re thermocouple (Fig. 5).

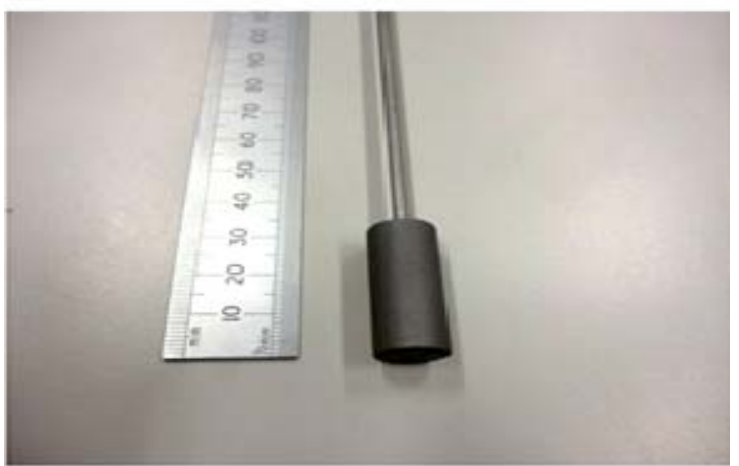

Figure 5: Incorporation of mini HTFP ingot with a metal sheathed tungsten rhenium (W-Re) thermocouple [15].

The test thermocouples are then placed in a furnace and raised in temperature to the melting point of the HTFP ingot. Each time the melting and freezing plateau was observed. For illustrative purposes see Fig. 6, but similar results have been obtained for all the HTFPs tested (up to the Ir-C point, $2292{ }^{\circ} \mathrm{C}$ ) [18].

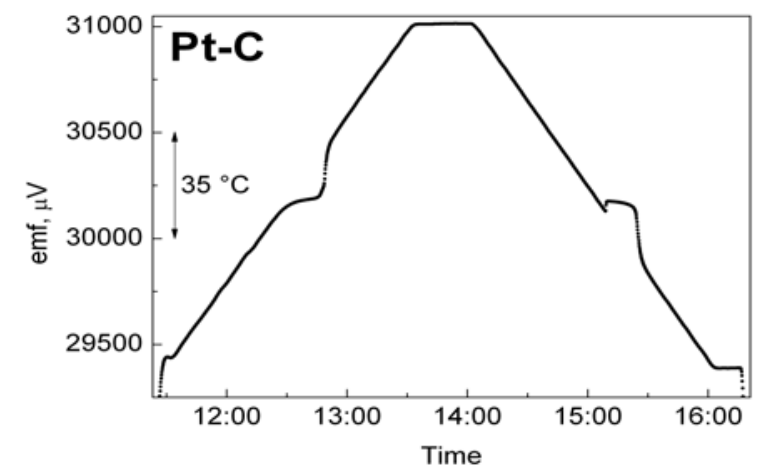

Figure 6: Typical Pt-C melt and freeze of the miniature HTFP (nominally $\left.1738^{\circ} \mathrm{C}\right)$, measured with a type $\mathrm{C}$ thermocouple [18].

It is clear that this transition can be used to normalize the thermocouple output and so maintain optimum control of a process. It has been shown $[15,18]$ that by implementing selfvalidation for type $\mathrm{C}$ thermocouples, instead of having to assign the manufacturing tolerance of $1 \%$ of temperature, the uncertainty could be about $2{ }^{\circ} \mathrm{C}-$ a potential factor of ten improvement in performance.

It should be noted that type $\mathrm{C}$ thermocouples generally operate in a vacuum or inert environment so there are no compatibility issues with the HTFP graphite crucibles, which are also compatible with the thermocouple tantalum sheathes.

In this section we have shown the possibility of improving high temperature thermometry in industry through proof of concept studies of self-validating W-Re thermocouples at high temperatures. However it is well known that there are a wide variety of unaddressed high temperature measurement problems in industry. Some of these are being tackled in a joint European Metrology Research Programme ${ }^{\text {(EMRP) project }}$ discussed briefly in the next section.

\section{THE HITEMS PROJECT}

HiTeMS, High Temperature Metrology for Industrial Applications, is a three-year, fifteen partner, research project part funded by the EMRP [19]. The objective of the research is to develop a suite of methods and techniques that will significantly improve the practice of industrial high temperature non-contact and contact thermometry, up to at least $2500{ }^{\circ} \mathrm{C}$. Special emphasis is given to facilitating in-situ traceability, i.e. ensuring traceability to the International Temperature Scale of 1990 (ITS-90) directly within the industrial process. This is often lost when industrial thermometry is performed due to (for example) unknown sensor drift or (for radiation thermometers viewing through windows) unquantified transmission changes.

The following outstanding problems with high temperature measurement will be addressed by this research:

Non-contact thermometry:

${ }^{1}$ Information about the EMRP can be found at: http://www.euramet.org/index.php?id=publicity 
- Emissivity and reflected radiation, with the target of achieving in-situ traceability

- Corrections for varying window/path transmission, to approximately $2500^{\circ} \mathrm{C}$

- Real time traceable temperature measurement in laser materials processing

Contact thermometry:

- Lifetime assessment of base metal and drift measurements of base and noble metal thermocouples

- $\quad$ Self-validation and demonstrated in-situ validation for temperature sensors to at least $2000{ }^{\circ} \mathrm{C}$

- Facility for determination of reliable reference functions for high temperature non-standard thermocouples (demonstrated by determining a better reference function for the Ir- $60 \% \mathrm{Rh} / \mathrm{Ir}$ thermocouple)

HiTeMS started in September 2011 and will conclude in Aug 2014. It is anticipated that by the end of the project many of the common problems encountered in industrial high temperature thermometry will have been addressed. More information about the project can be found at the HiTeMS website [20].

\section{SUMMARY}

An introduction to the international temperature scale of 1990 and temperature calibration has been given with special emphasis on traceability.

New high temperature fixed points were introduced and their significance in improving high temperature measurement described.

An overview of thermocouples has been given, how they work and their different types. This was followed by a description of inhomogeneity, the most common and least understood uncertainty, and the new thermocouple type based on pure thermoelements of $\mathrm{Pt}$ and $\mathrm{Pd}$.

The use of the principle of self-validation in making step change improvements in high temperature thermometry was outlined.

Finally a brief description of the EMRP project HiTeMS was given and its chief objectives described.

In summary the developments reported here show that a step change improvement in the practice of high temperature and in particular thermocouple thermometry is underway.

\section{ACKNOWLEDGMENTS}

The work described here was supported by the UK National Measurement Office, with additional support under a programme of, and funded by, the European Space Agency and the EMRP. The EMRP is jointly funded by the EMRP participating countries within EURAMET and the EU.
Thanks are given to Oijai Ongrai and Claire Elliott of NPL for providing some of the experimental results shown here, and Richard Rusby, of NPL, who gave valuable comments on this manuscript.

(C) Crown copyright 2012. Reproduced by permission of the Controller of HMSO and Queen's printer for Scotland.

\section{REFERENCES}

[1] H. Preston-Thomas, "The International Temperature Scale of 1990, ITS90", Metrologia, 1990, 27, pp. 3-10 and p. 127

[2] http://www.bipm.org/en/publications/its-90.html

[3] The International Vocabulary of Basic and General Terms in Metrology, ISO 1993

[4] G., Machin, "Twelve years of high temperature fixed point research: a review", Presented "The International Temperature Symposium (ITS9)", California, USA, Proceedings available from Autumn 2012.

[5] G. Machin, Dong Wei, M. J. Martín, D. Lowe, T. J. Wang, X. Lu, “A comparison of the ITS90 between, NPL, NIM and CEM above the silver point using High Temperature fixed points", Int. J. Thermophys., 31, pp. $1466-1476,2010$

[6] G. Machin, "Realising the benefits in improvements in high temperature measurement", Acta Metrologica, Sinica, 2008, 29, pp. 10-17

[7] J.V. Pearce, G. Machin, T. Ford, S. Wardle, "Optimising heat-treatment of gas turbine blades with a Co-C fixed-point for improved in-service thermocouples", Int. J. Thermophys., 29, pp. 222-230, 2008

[8] Thermocouple Temperature Measurement, Kinzie, P.A., WileyInterscience, 1973

[9] NPL Temperature Course Notes, 2012

[10] Manual on The Use of Thermocouples in Temperature Measurement, $4^{\text {th }}$ Edition, ASTM Manual Series: MNL 12, Revision of Special Technical Publication (STP) 470B (1993), BS EN (IEC) 60584-2, Specification for thermocouple tolerances, BSI, 1993

[11] http://srdata.nist.gov/its90/useofdatabase/use of database.html

[12] W.G. Burns, D.C. Ripple, M. Battuello, "Platinum versus palladium thermocouples, an emf-temperature reference function from $0{ }^{\circ} \mathrm{C}$ to $1500{ }^{\circ} \mathrm{C}$ ", Metrologia, 35, pp. 761-780, 1998

[13] F. Edler, R. Morice, J. Pearce,, "Construction and investigation of $\mathrm{Pt} / \mathrm{Pd}$ thermocouples in the framework of Euramet project 857”, Int. J. Thermophys., 29, pp. 199-209, 2008

[14] C. Elliott, J. Pearce, G. Machin, T. Ford, K. Hicks, "Pt/Pd thermocouple resilience over 327 operating hours in an industrial calibration laboratory"; Presented at "The International Temperature Symposium (ITS9)", California, USA, Proceedings available from Autumn 2012.

[15] O. Ongrai, J. Pearce, G. Machin, S. Sweene "Self-calibration of a W/Re thermocouple using a miniature $\mathrm{Ru}-\mathrm{C}\left(1954{ }^{\circ} \mathrm{C}\right)$ eutectic cell"; Presented at "The International Temperature Symposium (ITS9)", California, USA, Proceedings available from Autumn 2012.

[16] S. Augustin, F. Bernhard, D. Boguhn, A. Donin, and H. Mammen, "Industrially applicable miniature fixed-point thermocouples," in 8th International Symposium on Temperature and Thermal Measurement in Industry and Science (TEMPMEKO 2001), Berlin, 2001, pp. 3-8.

[17] ASTM E988, "Standard temperature-electromotive force (EMF) tables for tungsten-rhenium thermocouples", ASTM International, USA

[18] J. Pearce, C. Elliott, G. Machin, O. Ongrai, "Self-validating Type C thermocouples to $2300{ }^{\circ} \mathrm{C}$ using high temperature fixed points", Presented at "The International Temperature Symposium (ITS9)", California, USA, Proceedings available from Autumn 2012.

[19] G. Machin,, K. Anhalt, F. Edler, J. Pearce, M. Sadli, R. Strnad, E. Vuelban; "HiTeMS: A project to solve high temperature measurement problems in industry", Presented at "The International Temperature Symposium (ITS9)", California, USA, Proceedings available from Autumn 2012.

[20] http://projects.npl.co.uk/hitems/ 